\title{
O DIÁLOGO COMO CONDIÇÃO ÉTICA AO HUMANO QUE VEM
}

Clenio $\operatorname{Lago}^{(*)}$

A ruptura da metafísica implica compreender que não mais existem verdades, bases e modelos absolutos modelos referenciais absolutos, mas possibilidades, perspectivas, interpretações. A realidade abre-se em acontecimento. Nesse contexto, a medida transforma-se em desmedida mediante o dinamismo da realidade, para emergir como medida e novamente como desmedida. Radicaliza-se a autodeterminação individual como referência sobre o bem e o mal, para além ou aquém. A vontade é apresentada como soberana de si no lugar da razão, como o impulso básico a novos valores.

A exigência agora é que o homem precisa orientar, viver sua vida a partir de novos valores que não sejam os já estabelecidos culturalmente até então e dados como prontos e imutáveis, visto que esses estão desgastados e não servem mais. É preciso, acima de tudo, partir daqueles princípios que estejam voltados à afirmação da vida, para além da moral de rebanho, para além do bem e do mal: ser fiel a terra. Diferentemente da arte apolínea, Nietzsche (2005b, p. 9) aposta no princípio da arte dionisíaca, em que "o homem não é mais artista, tornou-se obra de arte [...]" e tudo o que o homem em sonho viu os deuses realizar, ele mesmo vive agora.

A diferença, o estranho, antes percebidos como algo perigoso e assimilado sob a reivindicação de igualdade, agora "[...] abre a chance de renovar periodicamente os objetivos da educação, que se desenvolvem através de uma diversidade de programas e expressem variantes de uma ideia de bem." (HERMANN, 2001, p. 134). Contudo, corre-se o risco relativismo, da banalização da diferença, do outro, de cair numa pobreza de experiência, na diversidade com espectro de violência e banalização do mal. O que vem agora? O que há de vir?

O ser que vem é o ser qualquer. [...] mas 'o ser que, seja como for, não é indiferente'; ele contém, dese logo, algo que remete para vontade (libet), o se qual-quer estabelece uma relação original o desejo.” (AGAMBEN, 1993, p. 11).

A proposições de Agamben (1993) em A comunidade que vem são indicativos exigentes para que pensemos sobre o humano que vem, que pode vir e educação pós ruptura da metafísica na medida que o ser que vem é o ser qualquer. Este, “[...] propriamente [...] o ser que pode não ser, que pode a sua própria impotência" (AGAMBEN, 1993, p. 33) coloca em questão a passagem da

\footnotetext{
(*) Doutor em Educação pela Pontifícia Universidade Católica do Rio Grande do Sul (2011); Mestre em Educação pela Universidade Federal de Santa Maria (2000). Professor do do Programa de Pós-Graduação em Educação da Universidade do Oeste de Santa Catarina (Unoesc).
} 
potência em ato, a realização de uma essência, de um telos, visto "a potência de não ser, pelo contrario, o acto não pode jamais constituir num simples trânsito de de pontentia as actum. (AGAMBEN, 1993, p. 34). Portanto, o homem é possibilidade, para além e a aquém do constumeiramente esperado, desejado e formado, por ser "[...] o único ser [...] que estrutura suas posibilidades sobre sua finitude" (SALVETTI, 2014, p. 60). Significa dizer com Agamben (1993, p. 38)

[...] o homem não é nem terá de ser ou realizar nenhuma essência, nenhuma vocação histórica ou espiritual, nenhum destino biológico [...] Isso não significa, todavía, que o homem não seja nem deva ser alguma coisa, que ele seja simplesmente entregue ao nada [...] é o simples facto da sua própria existencia como possibilidade ou potência.

Se o ser que pode vir é o ser qualquer, àquele que pode e que não pode sua potência, quais condições para um devir, para um vir ético? Qual educação?

É verdade que com a radical emergência da diversidade somos convocados a pensar e fazer educação para além do bem e do mal instaurados, como participantes de "[...] uma história mais elevada que toda a história até então!” (NIETZSCHE, 2005a, p. 147-148). Eis o desafio. No sentido de respondermos aos questionamentos postos, percorremos os seguintes pontos: o emergir do outro e sua notícia; o humano como acontecimento temporal - como temporalidade; o diálogo como condição ética ao humano que vem.

\section{A EMERGÊNCIA DO OUTRO}

Deixado de lado, subjugado, seja barbarizado, satanizado, esterilizado por discursos e práticas eugênicas, o outro que "[...] não possui destaque nem na metafísica nem na ética grega, embora seja analisado, de forma indireta, pelo princípio da identidade do ser" (HERMANN, 2014, p. 27), pois foi condicionado à identidade, caracterizado como não ser, como fonte do mal, castigado sem piedade, por um medo identitário, de a identidade perder. Mas foi esse outro, desde dentro e das margens do eu que fez ruir o paradigma dominante, evidenciando no apela a vida, sua doença, sua barbárie. Até então, “a dificuldade de lidar com o outro, e muitas vezes, seu aniquilamento, trouxe uma espécie de adoecimento, com desastrosas consequências para $\mathrm{O}$ plano político cultural e ético." (HERMANN, 2011, p. 3), visto que é também a dificuldade do eu lidar consigo mesmo.

"O emprego da palavra "outro" aparece associado ao estranho da identidade, a tudo que lhe é contrário, distinto e inverso." (HERMANN, 2011, p. 138). Emerge como um em si mesmo, como outra ontologia, mas que como encontro com também outro, é linguagem constitutiva 
autoconstitutiva, palavra que delineia uma relação original. Por isso, a "a alteridade é um outro, do qual depende a própria identidade. $\mathrm{O}$ outro e o eu estão numa relação complexa em que se remetem reciprocamente. Assim, o outro não só está fora como dentro do indivíduo." (HERMANN, 2006, p. 72). O outro é possibilidade de relação porque como outro em si, é, desde já, "interlocutor." (LEVINAS, 2004, p. 13). Encontro, desencontrar: interlocução.

O outro emerge assim, no cenário da modernidade, a partir do princípio da subjetividade como o estranho de mim mesmo, como aquilo que ultrapassa a identidade do eu, com identidade própria, como outra ontologia. Irrompe "[...] como um relato de experiência poética, expondo o deslocamento de uma concepção metafísica da identidade para uma concepção enraizada nos contextos plurais do mundo da via, que se vê diante da alteridade, num eu que é atravessado pelo outro.” (HERMANN, 2011, p. 138). Indica o estranho, aquilo que ultrapassa a identidade do eu.

A ruptura da metafísica possibilitou emergir possibilidades, vontades plurais: diversidade. Se antes os valores eram tidos como atemporais e unos, agora emergem como temporais e plurais, múltiplos, não existindo mais uma única perspectiva, senão que perspectivas. Assim, à medida que o outro como um em si aí emerge em possibilidade e se efetiva como outro aí, emerge configurando um novo tempo, o tempo originário, que dos, nos encontros e desencontros faz brotar o humano. A emergência do outro é também a emergência do humano em meio aos totalitarismos do eu e viceversa.

Que boa notícia traz o outro que nos chega? Que boa notícia sou e levo? Que "boa nova" emerge no encontro? O que vem agora? O humano enquanto acontecimento histórico, pois o viger do outro nos convoca a ultrapassarmos nossas próprias possibilidades subjetivas, colocando em jogo a nossa existência, tanto pela fala direta quanto pelo modo de ser, mas nunca em separado. Assim, o viger do outro é como o viger da obra que, como ser-aí, ressalta e suprime aspectos, diz algo, à medida que é algo para nós. "[...] todo aquele que faz a experiência da obra de arte acolhe em si a plenitude dessa experiência, e isto significa, acolhe-a no todo de sua autocompreensão, onde a obra significa algo para ele." (GADAMER, 2005, p. 16-17). A realidade constitui-se como acontecimento para além do bem e do mal subjetivos, totalitários, na medida em que emerge como abertura constitutiva, com solo fértil ao humano que vem. Mas como é possível este vir do humano, sem que o humano se perca? Quais condições?

Para esse momento convidamos Levinas e Gadamer, pensadores que abertamente lidam com o tema da alteridade, cada um a seu modo, mas com um ponto de inflexão comum: as provocações de Heidegger, a partir de Ser e tempo. 


\section{O HUMANO COMO ACONTECIMENTO ÉTICO}

Desde já perguntamos pelas possíveis contribuições e limites de Heidegger ${ }^{1}$ quanto à presença do outro como outro aí, como alteridade num contexto de pluralidades. Como podemos evidenciar a presença como elemento constitutivo do acontecer primordial do humano ${ }^{2}$, considerando que tal acontecimento constitui-se como acontecer formativo autoformativo do humano, dos diferentes que dos processos participam? No percurso de uma resposta vou valer-me, primeiramente, das contribuições de Levinas presentes na obra Entre nós: ensaio sobre a alteridade e seu diálogo entabulado com Heidegger a partir da obra Ser e tempo, com o apoio de Gadamer.

O questionamento que Levinas faz a Heidegger é fundamental: "A ontologia é a essência de toda relação com os seres e até de toda relação no ser. $\mathrm{O}$ fato de o ente ser 'aberto' não pertence ao próprio fato do seu ser?” (LEVINAS, 2004, p. 25); “[...] a alienação ontológica. Ela é, ao mesmo tempo, a primeira injustiça (LEVINAS, 2004, p. 53). Esse questionamento perpassa toda a obra como o grande ponto de inflexão do pensamento de Levinas.

A tese de Levinas $(2004$, p. 33) de que "O humano só se oferece a uma relação que não é poder" é um dos elucidativos dos limites do pensamento Heideggeriano à medida que evidencia que neste o mesmo se efetiva em sua mesmeidade na media em que quer compreender o outro, “[...] mas a relação (da alteridade) excede esta compreensão'. Significa que 'outrem não é,

\footnotetext{
${ }^{1}$ Com base na tese de que a cultura ocidental gerou o esquecimento do ser à medida que apostou no cientificismo, Heidegger revisou o grande projeto ocidental desde o retorno às coisas mesmas, proposto por Husserl, evidenciando que embora este tenha tematizado a questão do outro, não o fez sem pagar tributos ao cientificismo moderno. Para Husserl, inicialmente as coisas aparecem soltas e depois apareceu a consciência como unidade de sentido. Dessa forma, "[...] na visão dirigida sobre o objeto, temos, por exemplo, uma forma ou uma cor que permanece idêntica. Na atitude reflexiva, teremos os aspectos ou 'aparências' correspondentes, modalidades de orientação, de perspectiva, etc., que se sucedem numa sequência contínua" (HUSSERL, 2008, p. 57). Mas "a crítica heideggeriana visa à estreiteza de uma tal concepção de ser. [...]. O ser-aí não consiste na tentativa sempre ulterior de se colocar diante de si mesmo em meio ao tornar-se consciente de si. Ele é muito mais uma dação que se lança para além, e, em verdade, não apenas para as suas representações, mas antes de tudo para a não-dação do futuro (GADAMER, 2007, p. 18, v. II). De outra forma, “[...] a orientação pela subjetividade é tão determinante, que Husserl só conseguiu formular a partir daí até mesmo a colocação dos temas." (GADAMER, 2007, p. 19 v. II). Nisso constitui-se a diferença essencial entre Heidegger e Husserl, o que constitui a virada hermenêutica. Essa crítica de Heidegger a Husserl desemboca em uma crítica ao conceito de consciência como estrutura dogmática, para a qual Gadamer proporá a compreensão de consciência como consciência efeitual.

${ }^{2}$ Ursprung, em sua tradução para o português, tanto pode significar origem com originário. Em alemão a palavra Ursprung é formada pela palavra springen que é pular mais o prefixo $U r$ - o primordial, em que a essência da identidade constitui o pulo primordial - acontecimento. Nesse sentido, "Origem diz uma proveniência marcada por um começo e uma causa identificável, inscrevendo-se, portanto, no tempo interpretado linear e historicamente. Metafisicamente o começo e a causa foram identificados com a essência metafísica. Já originário diz algo bem diferente, pois foge a uma interpretação metafisica. Não se identifica nem com começo nem com causa enquanto essência. Por isso, outra é a concepção do tempo. É um tempo poético-ontológico que consiste em estar sempre principiando e constituindo realidade. [...] Ele é sem fundamento, é Ab-grund, é abissal, é misterioso. É nesse sentido que o alemão diz Ur-sprung: o salto originário, primordial" (SILVA; CASTRO, 2010, p. 226). O viger do outro, o encontrar-se como o outro constitui-se a possibilidade do eterno principiar.
}

Revista Teias, v. $17 \cdot$ v. $17 \bullet$ n. 47 (Out.-Dez., 2016): O avanço do conservadorismo nas políticas curriculares 
primeiramente, objeto de compreensão e depois, interlocutor'” (PIVATTO, 2004, p. 13), senão que, antes de tudo, o outro é interlocutor. Isso porque, “[...] a possibilidade do um-para-o-outro, um para o outro, que é o acontecimento ético." (LEVINAS, 2004, p. 17).

Por outro, a tese da ontologia heideggeriana que Levinas denuncia como a primeira causa da injustiça, parece configurar também uma condição prévia, sem a qual o outro pode emergir soberano, ou nem poder no seu simplesmente “é”, nos faz suspeitar: não há também uma ontologia do outro? Ontologias? É possível ainda economias do eu? Qual a finalidade da economia ${ }^{3}$ ? Aqui o terreno é muito escorregadio. Mas a questão é: qual a importância do prévio, do pré-conceito que na ontologia gadameriana constitui-se o absoluto, que na tradição iluminista é visto de modo negativo? O preconceito pode ser eliminado totalmente, ou ganha outra configuração? As proposições heideggerianas ainda tem sentido?

No ensaio de uma resposta, das presenças como rosto, enquanto rostos emergem como fundamental, à medida que se constituem em fachos de luz a iluminar, a gerar luzes. Portanto, Levinas no encontro com Heidegger é um convite para a reflexão em torno da diversidade como alteridade, no sentido do humano enquanto abertura constitutiva, enquanto interlocução. Mas o que significa a presença? O que significa rosto?

\begin{abstract}
A presença não é algo simplesmente dado que ainda possui de quebra a possibilidade de poder alguma coisa. Primariamente, ela é possibilidade de ser. Toda presença é o que ela pode ser e o modo em que é a sua possibilidade. A possibilidade essencial da presença diz respeito aos modos característicos de ocupação com o "mundo", de preocupação com os outros e, nisso tudo, à possibilidade de ser para si mesma, em função de si mesma. (HEIDEGGER, 2011, p. 203, grifo nosso).
\end{abstract}

O rosto como a própria identidade de um ser aí como a própria manifestação em acontecimento, o próprio dizer sem conceito exigindo desde já é interlocução, por ser desde já interlocução. É o que me arranca de minha hipótese, de minha primordialidade, que me desperta do sono dogmático convocando a um outro Que ser. Nas palavras de Levinas (2004, p. 59), “a presença sensível, aqui, se dessensibiliza para deixar surgir diretamente aquele que não ser refere senão a si, o idêntico. Como interlocutor ele se coloca em face de mim, e, propriamente falando somente o interlocutor pode se colocar em face, sem que 'em face' signifique hostilidade ou amizade." O outro desinstala a presença como um si para si em sua possibilidade, pois é invocação a ser, convocação a outro que ser, pois a particularidade de outro na linguagem, constitui a humanização (LEVINAS, 2004, p. 59). Por isso, o que Levinas rejeita de Heidegger e, com razão, é a “[...] possibilidade de [a

\footnotetext{
3 “A vontade produtora de obras é uma liberdade que se trai. Pela tradição é possível a sociedade - totalidade de liberdades, mantidas em sua singularidade, ao mesmo tempo que engajadas em uma totalidade. A relação do eu com uma totalidade é, portanto, essencialmente econômica" (LEVINAS, 2004, p. 54).
} 
presença, apenas] ser para si mesma, em função de si mesma" (HEIDEGGER, 2011, p. 203) à medida que afirma o problema em Heidegger é a reificação do mesmo, do círculo egoísta que vem desde Parmênides, em que o ser é e não pode não ser: a mesmeidade ontológica do pensamento ocidental do qual Heidegger é herdeiro e representante. Contudo, Levinas reconhece a importância do pensamento heideggeriano e o acolhe em seu movimento com a proposição do outro e do terceiro homem, à medida que "[...] o terceiro homem perturba esta intimidade." (LEVINAS, 2004, p. 41). Propõe no lugar do ser-com heideggeriano o um-para-o-outro. Assim, “[...] a possibilidade do um-para-o-outro, um para o outro, que é o acontecimento ético.” (LEVINAS, 2004, p. 17), do humano.

Agora, o outro é presença, bem como o eu para o outro, numa relação de face-a-face. A presença, que desde seu "pré", de seu modo de ser no encontro com outra presença instaura "círculos de compreensão" como um círculo formativo autoformativo, à medida que passa a responder aos desafios da contingência, mas também constitui realidade.

Mas, no encontro com as proposições de Levinas, o círculo da compreensão proposto por Heidegger ainda pode ser referenciado? Tal qual Heidegger o propõe não, pois tanto para Levinas quanto para Gadamer ${ }^{4}$ o ser-com heideggeriano constitui-se, respectivamente, como reificação do mesmo pelo não reconhecimento de outrem, e, por não considerar e inviabilizar a subjetividade. Para ambos, embora, o ser apareça como abertura, o ser-com heideggeriano não reconhece o outro devidamente, portanto, não consegue fundar o diálogo, mas constitui um prévio impossível de ser deixado de lado, para que haja diálogo, interlocução. "O homem é o único ser que não posso encontrar sem exprimir este encontro mesmo. [...] A relação com outrem, portanto, não é ontologia"

\footnotetext{
${ }^{4}$ Marcado pela analítica existencial efetivada por Heidegger, mas considerando a intersubjetividade como um processo aberto, portanto, histórico em que consciência se efetiva como consciência efeitual, Gadamer pergunta se o princípio do cuidado apresentado em Ser e tempo pode visualizar o outro de maneira adequada. Sua resposta é não, pois afirma que a proposição de Heidegger quanto ao cuidado inviabiliza a subjetividade e com isso a intersubjetividade, visto o ser-aí [heideggeriano] ser "[...] tão originariamente ser-com, quanto ele é ser-aí" (GADAMER, 2007, p. 22, v. II). Assim, o limite do pensamento de Heidegger está justamente em tomar o ser-aí na sua acepção ser-com, o que impede a presença do ser como diferenciação e como relação, como singularidade, pois "[...] aquilo que é visto assim, no ponto de partida heideggeriano, no horizonte da questão do ser exclui tão radicalmente o primado da subjetividade, que o outro não pode absolutamente se transformar em problema. 'Ser-aí' não é naturalmente subjetividade. Desse modo, em seu ponto de partida, Heidegger substituiu o conceito de subjetividade pelo conceito de cuidado. Nessa posição, contudo, fica claro que o outro só é visado com isso à margem e em uma perspectiva unilateral." (GADAMER, 2007, p. 22, v. II). Heidegger desvelou as bases estruturais da mais alta evidência da fenomenologia husserliana, em que, primeiro vejo um objeto e depois o reconheço como algo. Mas, ao evidenciar a estrutura do ser-aí como ser-com em Heidegger, Gadamer evidencia que, também Heidegger, não deu a devida atenção à questão do outro, à medida que o cuidado do qual o sercom heideggeriano participa, embora importante, anula o outro viger do outro.
} 
(LEVINAS, 2004, p. 28-29), é face a face, num indicativo de que o outro também o é ontologia, um pré a se colocado em jogo e a colocar em jogo.

Se pensadas como encontros ontológicos-negativos-constitutivos, no vir ao encontro presenças-rosto efetivam-se como possibilidade que podem acontecer para além do que lhes era viável sem o outro aí, sem o outrem. Agora, é invocada, convocada a ser outro modo que ser, num outro ato, como outra potência. No âmbito da alteridade podemos falar de ontologias que se encontram gerando fissuras ao mesmo da consciência que deixa de ser pensada a partir de suas necessidades e caprichos, mas que se abre como acontecimento, como possibilidade para além de suas possibilidades, num processo que se faz e se refaz presença. Isso porque

Outrem me arranca da minha hipótese, do aqui, do coração do ser ou do centro do mundo onde, privilegiado e, neste sentido, primordial, eu me coloco. Mas, neste arrancamento revela-se o sentido último da minha "minheidade". Na colocação do sentido de "eu" ao outro e também na minha alteridade a mim-mesmo, pela qual eu posso conferir ao outro o sentido do eu - o aqui e o lá invertem-se um no outro. (LEVINAS, 2004, p. 123).

O encontrar-se como experiência de alteridade constitui-se o próprio transcender da vida “[...] o próprio acontecimento da transcendência da vida" (LEVINAS, 2004, p. 124), enquanto dada na mesmeidade tanto do eu quanto do outro, seja enquanto consciência, seja enquanto estrutura psíquica seja enquanto cultura de vida. Assim também o é em Gadamer. Portanto, a experiência de alteridade é uma relação ética ao outro e também do eu, dos outros em relação a mim como o acontecer primordial do humano, via ruptura do que contém pelo que não pode ser contido, abrindose como experiência sempre principiante da vida como acontecimento, num eterno retorno do acontecer da vida que é a possibilidade de transcendência. É um movimento em que a alteridade de outrem e do eu não venha a ser banalizada ou ofuscar-se num simples "intercâmbio de bons comportamentos acordados", como um "comércio interpessoal” nos costumes (LEVINAS, 2004), num cessar de vida.

Como não vivemos num mundo em que existe apenas um primeiro chegar, mas vários fachos de luz é possível o pensar que se efetiva como encontro inter-humano (LEVINAS, 2004), intersubjetivo (GADAMER, 2005) visto que "a questão da minha consciência soberana não é mais a primeira questão.” (LEVINAS, 2004, p. 153). O outro é presença, como eu também o sou, e, enquanto tal, não é algo simplesmente dado, senão que é potencialidade um ser e um poder ser outro algo, possibilidade, acontecimento, potencial de alteridade expresso na singularidade. Por isso, a proposição de Levinas é "[...] pensar a socialidade como independente da unidade "perdida"” (LEVINAS, 2004, p. 154), algo possível para a emergência reconhecida do outro, como acontecimento de outros modos que ser. Do contrário, o eu enquanto eu puro fechado em mim 
mesmo petrifica, objetifica o outro; e o outro enquanto outro puro em si, fechado em si mesmo petrifica o eu, a realidade.

É nesse sentido que "o dinamismo do pensar supõe a relação com o diferente, requer a mediação de um outro que, curiosamente, torna possível o discurso, o logos, a razão. [...] O outro [...] como o estrangeiro [...] é aquele que só pode comparecer na medida em que já provocou uma reação responsiva, no interior de uma esfera própria.” (FABRI, 2006, p. 144). Portanto, “a surpresa trazida pelo outro é uma espécie de impedimento da harmonização definitiva [...] (FABRI, 2006, p. 145)", uma vez que rompendo com a mesmice do sistema exigindo o repensar de paradigmas. Por isso, "a alteridade é um outro, do qual depende a própria identidade. $\mathrm{O}$ outro e o eu estão numa relação complexa em que se remetem reciprocamente" (HERMANN, 2006, p. 72), de onde dependa a compreensão.

Para o momento: uma boa alternativa de resposta às questões acima é a própria subversão do pensamento de Heidegger (2011, p. 2014) no contexto da diversidade enquanto alteridade, excepcionalmente, quanto ao conceito de círculo da compreensão ${ }^{5}$ na chamativa de que o círculo da compreensão não pode se perder em círculo vicioso, pois nele se esconde a possibilidade do acontecer mais originário, o que Gadamer (2005) muito bem desenvolve com posição do jogo dialógico, em Levinas (2004) interlocução. Portanto, “O decisivo não é sair do círculo, mas entrar no círculo de modo adequado.” É com esse cuidado, portanto, que deveríamos andar.

Como é possível potencializar essa condição de abertura do humano? $\mathrm{Na}$ emergência da diversidade, o aparecimento do outro enquanto outro aí diverso de mim chama atenção para que ultrapassemos a reificação do mesmo e a pura reificação do outro e nos instemos para além do bem e do mal, como acontecimento ético. Como é possível ultrapassar esta proposição? O indicativo do terceiro, de terceiros, no face a face. Ou como é possível a formação no horizonte do acontecer primordial do humano, sem nos obliterarmos em dificuldades, sem que a diversidade configure sinônimo de conflito, mas sinônimo de diálogo, de interlocução?

\footnotetext{
5 "O decisivo não é sair do círculo, mas entrar no círculo de modo adequado. Esse círculo do compreender não é um cerco em que se movimenta qualquer tipo de conhecimento. Ele exprime a estrutura-prévia existencial, própria da presença. O círculo não deve ser rebaixado a um vitiosum, mesmo que apenas tolerado. Nele se esconde a possibilidade positiva do conhecimento mais originário que, de certo, só pode ser apreendida de modo autêntico se a interpretação tiver compreendido que sua primeira, única e última tarefa é de não se deixar guiar, na posição prévia, visão prévia e concepção prévia, por conceitos populares e inspirações. Na elaboração da posição prévia, da visão prévia e concepção prévia, ela deve assegurar o tema científico a partir das coisas elas mesmas. Porque, de acordo com seu sentido existencial, compreender é o poder-ser da própria presença [...]" (HEIDEGGER, 2011, p. 214-215).
} 


\section{Construir pontes: necessário, mas não suficiente}

O homem é uma corda destendida entre o animal e o super-homem: uma corda sobre o abismo; travessia perigosa, temerário caminhar perigoso olhar para trás, perigoso temer e parar.

A grandeza do homem é ser uma ponte, e não uma meta; o que se pode amar no homem é ser ele uma passagem e um termo.

Amo apenas aqueles que sabem viver como que se extinguindo, porque esses são os que atravessam de um lado para o outro.

Amos os soberbos, porque são os grandes adoradores, as setas da cobiça ansiosas pela outra margem. [...]

Amo o que não preserva para si uma gota de seu espírito, mas que deseja ser inteiramente o espírito da sua eqüidade, porque assim cruza a ponte como espirito (NIETZSCHE, 1985, p. 11-12).

É temerário trazer as intensas provocações de Nietzsche, em poucas e sucintas palavras, mas as trago como convite à reflexão de que além de ser necessário construir pontes é necessário lançarse mais para além do bem e do mal, como forma de compreender o tema do acontecer primordial do humano como um eterno principiar da vida. E mais, como fica o ser desprendido de seu sol? De onde brota a luz, a consciência agora e como este se constitui? É a consciência também acontecimento histórico. "A consciência faz e refaz presença - ela e a vida da presença" e o viver da presença." (LEVINAS, 2004, p. 101).

Os indicativos de Nietzsche são fortes na medida em que evidencia a vida em devir e não me permitem passar despercebidos também para esta homenagem, à medida que evidencia o humano em sua existencialidade. Diz Nietzsche "Onde encontrei um ser vivente, lá encontrei vontade de poder. E, este mistério segredou-me a vida: 'Veja', disse ela, 'eu sou aquela que sempre tem de superar a si mesma'." (NIETZSCHE apud GIACOIA JÚNIOR, 2005, p. 58). Por outro, que Nietzsche (1989, p. 77) indica que "não existe Coisa-em-si, nenhum conhecimento absoluto; o caráter perspectivista, ilusório, enganador é intrínseco à existência"; que o conhecimento é ““Interpretação', de modo algum 'explicação'.” (NIETZSCHE, 1989, p. 88). Por isso o “"Eu' tratase de uma hipótese auxiliar com vista à inteligência do mundo." (NIETZSCHE, 1989, p. 73). E nisso somos vontades de potência e, de modo algum, coisas objetivas e objetáveis, diz Nietzsche, chamando a atenção para a intersubjetividade radical, a intersubjetividade acontecendo, nos e pelos encontros e desencontros, como um processo aberto, complexo como uma corda, ou cordas lançadas no abismo da temporalidade, a constituir-se no reinventar-se.

Portanto, no avançar de nossa argumentação sobre os limites da subjetividade, é importante a advertência de Hegel a Kant quanto aos limites da subjetividade moderna, ao propor a intersubjetividade com um dos momentos constitutivos da subjetividade, aqui tomada sem os propósitos do idealismo absoluto.

Mas a subjetividade implica o que é diferente de si e o poder de se opor e tratar o diferente como algo de negativo. É a negatividade infinita, a negação, e a natureza representa esta 
última. Tal idealidade e tal negatividade infinita formam o conceito profundo da subjetividade do espírito. Mas enquanto subjetividade, o espírito ainda não é mais do que a verdadę đă natureza, visto que ainda não formou o conceito de si para si. (HEGEL, 2005, p. 118, grifo do autor).

$\mathrm{O}$ argumento da interdependência, da intersubjetividade, evidencia o equívoco em tomar o indivíduo apenas enquanto subjetividade, sem considerar que este se constitui na relação intersubjetiva aberta que se efetiva num e com um redemarcar de identidades. Mas, o argumento de Hegel articulado com o argumento de Nietzsche evidencia a impossibilidade do verdadeiro reconhecimento, enquanto as relações estruturadas numa interdependência previamente, dada, ou acabada, ou puramente assimetria.

A presença no encontro com o outro, não é apenas um estar aí, mas um ser aí acontecendo, uma exigência de que reconheçamos " [...] em princípio o caráter limitado do próprio projeto, mas exige precisamente que alcancemos um âmbito para além das próprias possibilidades no interior do processo dialógico, comunicativo, hermenêutico" (GADAMER, 2007, p. 23-24) como chamado ao infinito. Nas palavras de Levinas, que o humano se efetive como transcendência, pois a presença, o outro, num encontro dos aí coloca em jogo as subjetividades, os modos de ser, num acontecer que “[...] não tem dono e que a importância particular dessa ou daquela observação como tal não é decisiva para sua instauração [...]" (GADAMER, 2005, p. 461), visto ser um processo não dominável por nenhum dos participantes.

Assim, o encontro com o legítimo outro legítimo instaura a intersubjetividade radical, experiência na qual nos tornamos conscientes de nossa condição da finitude como infinitude de nossa temporalidade, à medida que implica o reconhecimento de que devo estar disposto a deixar valer em mim algo contra mim, ainda que não haja nenhum outro que vá fazer valer algo contra mim (SILVA, 2014). É o encontro dialógico com o outro que possibilita a experiência efetiva na sua maior autenticidade "[...] como consciência da história efeitual" (GADAMER, 2005), em que a própria consciência se efetiva como histórica, como acontecimento. Uma experiência autêntica que implica mútua abertura ao diálogo, pertença recíproca, “[...] possível quando sempre e ao mesmo tempo pode-se-ouvir-uns-aos-outros." (SILVA, 2014, p. 86).

Nesse cenário, o “"Preconceito’ não significa, pois, de modo algum, falso juízo, uma vez que seu conceito permite que ele possa ser valorizado positiva ou negativamente" (GADAMER, 2005, p. 360), visto ser possibilidade de abertura, de jogo, diferentemente do que ocorre na tradição Iluminista da Aufklärung, em que o preconceito aparece com algo falso, gerando “[...] a submissão 
de toda a autoridade à razão." (GADAMER, 2005, p. 369). E, a negação do outro e/ou do eu ante ao puro saber, ou ao puro eu ou ao puro outro elimina o caráter histórico da condição humana.

Baseada no reconhecimento da diversidade e no jogo dialógico como estrutura da experiência de alteridade, a proposição hermenêutica, conforme apresentada por Gadamer, sugere ser importante a forma como acolhemos, dirigimo-nos ao outro, embora não totalmente controláveis. Por isso que

[...] o modo como experimentamos uns aos outros, como experimentamos as tradições históricas, as ocorrências naturais de nossa existência e de nosso mundo, é isso que forma o verdadeiro universo hermenêutico. Nele não estamos encerrados como entre barreiras intransponíveis; ao contrário, estamos sempre abertos para o mundo. (GADAMER, 2005, p. 32).

Diferentemente da proposição de verdade científica ancorada no experimento como controle das variáveis, em que uma das exigências é a negação inicial de todo e qualquer preconceito, a verdadeira experiência é a “[...] experiência da própria historicidade” (GADAMER, 2005, p. 467), em que o ser humano se efetiva como humano, como acontecer na intersubjetividade radical, na mútua redemarcação das identidades num desafio de ser outro. É a experiência na qual me transformo, a qual a realidade se transforma em outra. Nesse processo, "o que vem à tona, na sua verdade, é o logos que não é nem meu e nem teu, e que por isso sobrepuja tão amplamente a opinião subjetiva dos companheiros de diálogo [...]” (GADAMER, 2005, p. 480). Mas, mais do que isso, o além do homem, num ressignificar do bem e do mal.

Resultando na redemarcação das identidades em jogo, o diálogo autêntico gera transformação em configuração. "[...] significa que algo se torna uma outra coisa, de uma só vez e como um todo, de maneira que essa outra coisa em que se transformou passa a constituir o seu verdadeiro ser, em face do qual o seu ser anterior é nulo. [...] que aquilo que era antes não é mais." (GADAMER, 2005, p. 166). Isso porque, o humano “tem o caráter de obra, do ‘ergon' e não somente da 'energia'." (GADAMER, 2005, p. 165). Pode configurar-se, não somente em outro ato, senão que em outra potência: um outro modo que ser, no sentido de "vontade de potência de alteridade." (LAGO; FARINON, 2014, p. 768).

Sendo assim, o indicativo de Morin (2001), de procurar comunicação entre a esfera dos objetos e a dos sujeitos faz sentido, mas não é suficiente, porque somos interlocução (LEVINAS, 2004), ou mesmo diálogo (GADAMER, 2005), visto que do jogo, ou do diálogo autêntico nunca nos volvemos os mesmos. Transformamo-nos a partir das potencialidades de nossas presenças, no encontro com outras potencialidades, nos ressignificamos em meios aos encontros e desencontros. 
Ou seja, a realidade muda e nós também. Por isso, o desafio da educação é o do entretecimento, do humano como acontecer originário originante, como temporalidade, no horizonte das relações que vão se tecendo. De outra forma, quando chegamos o outro, o eu e os outros não somos aí, ou lá e acolá como dados, estanques, visto a realidade mudar e nós também. Somos acontecimento, interlocução, pois se chegamos lá, o lá não mais é, é acontecimento, abertura. É transformação em configuração. Como é possível potencializar essa condição de abertura do humano?

$\mathrm{Na}$ emergência da diversidade, o aparecimento do outro enquanto outro aí diverso de mim chama atenção para que ultrapassemos a reificação do mesmo e a pura reificação do outro e nos instemos para além do bem e do mal, como acontecimento ético. Como é possível ultrapassar esta proposição? O indicativo do terceiro, de terceiros, no face a face. Ou como é possível a formação no horizonte do acontecer primordial do humano, sem nos obliterarmos em dificuldades, sem que a diversidade configure sinônimo de conflito, mas sinônimo de diálogo, de interlocução?

\section{O DIÁLOGO COMO MODO DE SER ÉTICO DO ACONTECER HUMANO}

\section{[...] pode haver periodos em que o humano se extingue completamente [...].} (LEVINAS, 2004, p. 157).

[...] a capacidade constante de voltar ao diálogo, isto é, de ouvir o outro, parece-me ser a verdadeira elevação do homem à sua humanidade. (GADAMER, 2004, p. 251).

O encontro com uma grande obra de arte, que é outro, é sempre um diálogo fecundo, do qual algo emerge e permanece. Numa proximidade a compreensão estética em Gadamer, Levinas (2004, p. 32), ao falar do rosto, como significando outramente, se pergunta se as coisas podem tomar um rosto: “A arte não é uma atividade que confere rosto às coisas? A fachada de uma coisa não é uma casa que nos olha?"

De outra maneira, o encontro com o outro dá o que falar, faz emergir algo, à medida que exige um ter que responder. Gera transformação em configuração, o que "[...] significa que algo se torna uma outra coisa, de uma só vez e como um todo, de maneira que essa outra coisa em que se transformou passa a constituir o seu verdadeiro ser, em face do qual o seu ser anterior é nulo. [...] significa que aquilo que era antes não é mais.” (GADAMER, 2005, p. 166). Por isso, o “[...] um diálogo levado a sério, que não se oblitera em dificuldades, pressupõe entrar no jogo com o outro. A palavra que circula no diálogo desvela, questiona, configura identidades, demarca diferenças." (HERMANN, 2002, p. 94). Nesse sentido, o ser humano “tem o caráter de obra, do 'ergon' e não somente da "energia"' (GADAMER, 2005, p. 165), tem o caráter de ato e potência, que no encontro com outro ato e potência pode fazer emergir novos atos, novas potências, o que é impossível sem o 
encontro entre diversos, como também quem do diálogo participa é convidado emergir em outro ato em outra potência, como um outro modo de ser. O outro nos lança a pergunta de um outro modo que ser, cabendo-nos a resposta.

O diálogo efetiva-se no horizonte do perguntar e do responder, à medida que vai colocando à prova os argumentos, as respostas e o próprio perguntar. Assim, “opondo-se à rigidez das opiniões, o perguntar [o outro] põe em suspenso o assunto com suas possibilidades.” (GADAMER, 2005, p. 479). Mas, a fim de que o diálogo se efetive, é necessário reconhecimento mútuo, abertura por partes dos que participam ou venham a participar do diálogo, de maneira fundamental. Devem estar em condições de deixar valer algo contra si. Implica abertura mútua, que somente se efetiva com base na pertença, pois "sem essa abertura mútua, tampouco pode existir verdadeiro vínculo humano. A pertença mútua significa sempre e ao mesmo tempo poder ouvir uns aos outros." (GADAMER, 2005, p. 472). Exige o reconhecimento de que o outro, a tradição, de que o eu, de que o presente tenha algo a dizer. Mais do que isso, que nenhum indivíduo, em sua subjetividade, contém a verdade, senão que a verdade emerge no jogo, como histórica. Isso requer "[...] a capacidade constante de voltar ao diálogo, isto é, de ouvir o outro, parece-me ser a verdadeira elevação do homem à sua humanidade." (GADAMER, 2004, p. 251). Ou seja, é a capacidade de efetivar-se no acontecer do ser como possibilidade pelo reconhecimento.

Podemos afirmar que o diálogo efetiva-se como o jogo, pois tem imbricado em seu ser a estrutura do perguntar e do responder na medida em que no encontro com o outro, ultrapassa a subjetividade de cada jogador e o jogo ganha vida própria, liberando o ser como devir com possibilidade. "O que vem à tona, na sua verdade, [no encontro com o outro] é o logos que não é nem meu e nem teu [...]" (GADAMER, 2005, p. 480). Nas palavras de Nietzsche (2005), um novo mármore é talhado, o Homem. Portanto, "o homem não é mais artista, tornou-se obra de arte [...]", que no encontro com o outro se efetiva como acontecimento do nascimento, obra em obra (LAGO, 2014). Isso porque, no espírito do diálogo como no jogo em que o acontecer não tem dono, mas que depende da mútua participação.

[...] os participantes vêem-se referidos, por assim dizer, enlaçados uns aos outros, sendo que jogo exige a entrega de cada um a um processo não dominável por nenhum dos participantes. Quem estiver, inicialmente, certo de ter elaborado o caminho mais adequado à vitória, vê-se surpreendido, de repente, por um lance inesperado do outro, ao qual não consegue, mas corresponder à altura. [...] O sentido nasce do "vir ao encontro" de um outro, eu-tu, eu-texto, eu-obra de arte, etc. (FLICKINGER, 2003, p. 173).

A formação enquanto autoformação possível enquanto diálogo autêntico constitui-se como acontecimento ético. É “[...] o lugar onde essa fusão se dá constantemente, pois nela o velho [o eu] 
e o novo [o outro] sempre crescem juntos para uma validez vital, sem que um e outro cheguem a se destacar explícita e mutuamente" (GADAMER, 2005, p. 404-405), para além do dado, do dito, no dizer. Portanto, “é o Dizer que vai do Mesmo ao Outro, sem suprimir a diferença. [que] Abre passagem lá onde nada é comum.” (LEVINAS, 2004, p. 96).

Agora, a educação, antes de ser um processo meramente reprodutivo, no horizonte do encontro com o outro, efetiva-se como acontecimento constitutivo autoformativo, em que a consciência se efetivada como finitude infinita, como acontecer originário a principiar em nascimento. "Mas o verdadeiro acontecer só se torna possível pelo fato de a palavra [o outro] que chega a nós como tradição [como outra tradição] e que devemos ouvir nos atingir realmente, como se fosse dirigida a nós e se referisse a nós mesmos." (GADAMER, 2005, p. 595-596).

O outro nos coloca em jogo, como o eu coloca em jogo o outro, o terceiro que nos chega, podendo, ao mesmo tempo romper com a mesmeidade do eu quanto do outro. Assim, "o modo como experimentamos uns aos outros, como experimentamos as tradições históricas, as ocorrências naturais de nossa existência e de nosso mundo" (GADAMER, 2005, p. 32) passa a ser crucial, pois ao se deparar com o outro, o eu se depara consigo e se efetiva como consciência histórica, como temporalidade, no outro, com o outro e como outro, como abertura, como possibilidades de outros modos que ser.

\section{CONSIDERAÇÕES FINAIS}

A ruptura da metafísica constitui a possibilidade do emergir do outro no reconhecimento enquanto outro aí, a diversidade enquanto alteridade, como condição para o diálogo autêntico, enquanto acontecimento que não se oblitera em dificuldades, seja pelo conflito na diferenciação absoluta, seja enquanto síntese, seja enquanto disputa. Mas, o emergir do outro é também a emergência do humano no sentido dúbio que a palavra se presta na linguagem, seja enquanto aparecimento e, enquanto, urgência.

O diálogo autêntico demarca, configura, significa, ressignifica identidades em meio ao horizonte comum, pois é acontecimento ético originário em que o humano humana sempre a principiar. Assim, se o humano somente se revela numa relação que não é poder, portanto é interlocução, podendo haver momentos em que se extingue totalmente (Levinas 2004), a capacidade de dialogar, de voltar ao dialogo, constitui-se a possibilidade da humanidade (GADAMER, 2004). Portanto, que o humano que vem só poderia vir enquanto acontecimento ético via diálogo autêntico, 
tanto como condição à ética ao humano que vem como a própria condição de devir do humano que pode vir. Do contrário, ausência do humano. 


\section{REFERÊNCIAS}

AGAMBEN, G. A comunidade que vem. Trad.: António Guerreiro. Lisboa/Portugal: Editorial Presença, 1993. 86 p.

CARBONARA, V. Educação, ética e diálogo desde Levinas e Gadamer. Tese (Doutorado em Educação) - Pontifícia Universidade Católica do Rio Grande do Sul, Porto Alegre, 2013, 170 p. Disp.: <: http://repositorio.pucrs.br/dspace/ handle/10923/2900>. Acesso: set. 2016.

CASTRO, M. A. Notas de tradução. In.: HEIDEGGER, Martin. A origem da obra de arte. Trad.: Idalina Azevedo; Manuel Antônio de Castro. São Paulo: Edições 70, 2010, p. VII-XXXI.

FABRI, M. Harmonização e estranhamento: a proposta de uma fenomenologia responsiva. In: TREVISAN, Amarildo Luiz; TOMAZETTI (Org.). Cultura e alteridade: confluências. Ijuí: UNIJUÍ, 2006. p. 143-155.

FLICKINGER, H-G. O fundamento ético da hermenêutica contemporânea. Veritas, Porto Alegre, v. 48, n. 2, p. 169179, jun. 2003. Disp.: < http://biblat.unam.mx/pt/revista/veritas-porto-alegre/articulo/o-fundamento-etico-da-hermeneu tica-contemporanea>. Acesso: set. 2016.

GADAMER, H-G. Verdade e método I: traços fundamentais de uma hermenêutica filosófica. 7. ed. Trad. Enio Paulo Giachini. Petrópolis, RJ: Vozes; Bragança Paulista, SP: Ed. Universitária São Francisco, 2005. 631 p.

Verdade e método II: complemento e índice. 2. ed. Trad.: Enio Paulo Giachini; revisão: Marcia Sá Cavalcante Schuback. Petrópolis, RJ: Vozes; Bragança Paulista, SP: Ed. Universitária São Francisco, 2004. 621 p.

Estética y hermenéutica. 3. ed. Introdução: Angel Gabilondo; trad.: Antonio Gómez Ramos. Madrid, Espanha: Tecnos, 2006, 316 p.

. Hermenêutica em retrospectiva: a virada hermenêutica. Trad.: Marco Antônio Casanova. Petrópolis: Vozes, v. 2, 2007. 212 p.

GIACOIA JUNIOR, O. Nietzsche. São Paulo: Publifolha, 2000. 92 p.

HEGEL, G. W. F. Estética. Trad.: Orlando Vitorino. São Paulo: Nova Cultural, 2005. 464 p. (Col. Os Pensadores).

HEIDEGGER, M. Ser e tempo. Trad.: Márcia de Sá Cavalcante Schuback. Petrópolis: Vozes; Bragança Paulista: Ed. Universitária São Francisco, 2011, 598 p.

. A origem da obra de arte. Trad.: Idalina Azevedo; Manuel Antônio de Castro. São Paulo: Edições 70, 2010. $252 \mathrm{p}$.

HERMANN, N. Educação e ética: outra sensibilidade. Belo Horizonte: Autêntica, 2014. 175 p.

. Autocriação e horizonte comum: ensaios sobre a educação ético-estética. Ijuí: Unijuí, 2010. 171 p.

. Breve investigação genealógica sobre o outro. Educação \& Sociedade, Campinas, v. 32, n. 114, jan./mar. 2011. Disp.: < http://www.scielo.br/pdf/es/v32n114/a09v32n114.pdf $>$. Acesso: set. 2016.

Ética, Estética e Alteridade. In: TREVISAN, A.L.; TOMAZETTI, E. (Org.). Cultura e alteridade: confluências. Ijuí: Unijuí, 2006. p. 61-77.

. Fhronesis: a especificidade da compreensão moral. Educação: Porto Alegre, RS, ano 30, v. 2, n. 62, p. $365-$ 376, maio/ago. 2007. Disp.: <http://revistaseletronicas.pucrs.br/ojs/index.php/faced/article/viewFile/563/393 >. Acesso em 16 set. 2016.

. Hermenêutica e educação. Rio de Janeiro: DP\&A, 2002. 109 p.

. O outro na intersubjetividade. In: BOMOBASSARO, Luiz Carlos; DALBOSCO, Cláudio Almir; KUIAVA, Evaldo Antonio. Pensar sensível. Porto Alegre: PUCRS, 2011. p. 433-443.

. Pluralidade e ética em educação. Rio de Janeiro: DP\&A, 2001. 147 p.

LAGO, C. Experiência estética e formação: articulação a partir de Hans-George Gadamer. Porto Alegre, RS: EDIPUCRS, 2014. 115 p.

LAGO, C; FARINON, M. J. A educação no horizonte da construção linguística. Revista Brasileira de Educação, v. 19, n. 58, jul./set. 2014. Disp.: < http://www.scielo.br/pdf/rbedu/v19n58/12.pdf>. Acesso: 16 set. 2016.

LEVINAS, E. Entre nós: ensaio sobre a alteridade. 3. ed. Petrópolis: Vozes, 2004. 302 p.

Revista Teias, v. 17 • v. 17 • n. 47 (Out.-Dez., 2016): O avanço do conservadorismo nas políticas curriculares 
MORIN, E. Ciência com consciência. 5. ed. Trad.: Maria D. Alexandre e Maria Alice Sampaio Dória. Ed. Revista e ampliada pelo autor. Rio de Janeiro: Bertrand Brasil, 2001, 344 p.

NIETZSCHE, F. Assim falava Zaratustra. Trad.: Eduardo Nunes Fonseca. São Paulo: Hemus, 1985. 262 p.

A gaia ciência. Trad., notas e prefácio: Paulo César de Souza. São Paulo: Cia das Letras, 2005a 362 p.

. A visão dionisíaca de mundo: e outros textos de juventude. Trad.: Marcos Sinésio Periera Fernandes; Maria

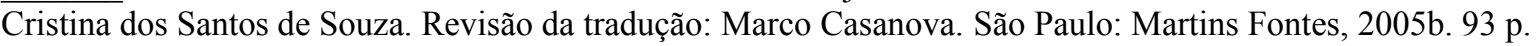

. Ontologia de textos de Nietzsche sobre a teoria do conhecimento. Sujeito e perspectivismo. Seleção de textos de Nietzsche sobre a teoria do conhecimento. Introdução e notas: Antonio Marques. Portugal: Publicações Dom Quixote Ltda, 1989. p. 64-104.

PIVATTO, P. S. Apresentação. In: LÉVINAS, Emmanuel. Entre nós: ensaio sobre a alteridade. 3. ed. Trad.: Pergentino Stefano Pivato (coord.); Evalto Antônio Kuiava; José Nedel; Luiz Pedro Wagner; Macelo Luiz Pelizolli. Petrópolis: Vozes, 2004

SALVETTI, E. F. A comunidade que vem: uma tarefa ética em Giorgio Agamben. Profanações, Ano 1, n. 2, p. 48-69, jul./dez., 2014. Disp. : <http://www.periodicos.unc.br/index.php/prof/article/viewFile/710/449>. Acesso: 16 set. 2016.

SILVA, D. J. S. Apontamentos sobre a experiência do outros, amizade e solidariedade em H. G. Gadamer. PERI, v. 06, n. 01, p. 77-98, 2014. Disp.: <http://nexos.ufsc.br/index.php/peri/article/view/908/411>. Acesso: 16 set. 2016.

\section{RESUMO}

Em meio aos desafios que emergem com a ruptura da metafísica, perguntamos pelo que pode vir, pelas condições éticas ao humano vem enquanto potência e impotência de ser, enquanto possibilidade, sem que este caia em puro relativismo e ou dogmatismo, mas que possa se efetivar enquanto acontecimento ético gerativo. Portanto, qual educação? Como base em que principios geradores? Aquí, indicamos o diálogo autêntico, o que não se oblitera em dificuldades, como condição à radical experiência de alteridade e condição ética ao humano que vem. Isso porque, como nos mostram dadas experiências, sinalizadas, não somente por Levinas, há momentos em que o humano se extingue.

Palavras-chaves: Ruptura da metafísica. Alteridade. Educação.

\section{DIALOGUE AS A CONDITION ETHICS HUMAN COMING}

Among the challenges that emerge with the rupture of metaphysics, we ask for what may come, the ethical conditions for human comes as power and impotence of being, as a possibility, without it falling into pure relativism and or dogmatism, but it can be effective while ethical generative event. So what education? Based on principles that generators? Here we show authentic dialogue, which obliterates not in trouble, as a condition to the radical otherness of experience and ethical human condition to come. This is because, as experience shows us given, marked not only by Levinas, there are times when the human is extinguished.

Keywords: Break metaphysics. Otherness. Education.

Submetido em Ago./2016

Aprovado em Nov./2016

Revista Teias, v. 17 • v. 17 • n. 47 (Out.-Dez., 2016): O avanço do conservadorismo nas políticas curriculares 